\title{
Avaliação do plano nacional de prevenção, preparação e resposta rápida a emergências ambientais no transporte rodoviário de Produtos Perigosos (P2R2): Estudo de caso BR 393
}

\author{
Evaluation of the National Plan for the Prevention, Preparation and Rapid Response to Environmental \\ Emergencies in Road Transport of Hazardous Products (P2R2): BR 393 Case Study
}

Alexandre da Silva Souza*, Irineu Vieira da Silva Júnior, Jonas dos Santos Pacheco, Cristiane de Souza Siqueira Pereira

Como citar esse artigo. Souza, AS; da Silva, IV; Pacheco, JS; Pereira, CSS. Avaliação do plano nacional de prevenção, preparação eresposta rápida a emergências ambientais no transporte rodoviário de Produtos Perigosos (P2R2): Estudo de caso BR 393 Revista Teccen. 2018 Jul./Dez.; 11 (2): 02-08.

\begin{abstract}
Resumo
Os acidentes ambientais são caracterizados como eventos não planejados e indesejados que podem causar, direta ou indiretamente, danos ao meio ambiente e à saúde da população. O desenvolvimento econômico de uma sociedade conduz ao crescimento do consumo industrial de produtos químicos e perigosos e, o transporte rodoviário com regulamentações e base em legislação e critérios técnicos é uma das principais atividades que possibilitam as movimentações desses materiais. Este trabalho tem o propósito de avaliar os pontos mais susceptíveis a acidentes com riscos ambientais e sociais, envolvendo o transporte rodoviário de produtos químicos e perigosos da Rodovia BR 393, denominada Rodovia Lúcio Meira. O trecho estudado correspondeu ao Km 282 (limite Municipal da cidade de Volta Redonda e da cidade de Barra do Piraí) ao Km 246 (limite Municipal da cidade de Barra do Piraí e da cidade de Vassouras). Buscou-se avaliar os pontos mais susceptíveis a acidentes com riscos ambientais, bem como a identificação, classificação e as ações de emergência das cargas transportadas. Sendo assim, podendo elaborar medidas para um plano de emergência preventivo e integrado entre os Municípios citados, evitando impactos ambientais provenientes de acidentes e as ações corretivas caso eles aconteçam.

Palavras-Chave: Transporte rodoviário; Produtos perigosos; P2R2.
\end{abstract}

\begin{abstract}
Environmental accidents are characterized as unplanned and unwanted events that can directly or indirectly cause harm to the environment and the health of the population. The economic development of a society leads to the growth of industrial consumption of chemical and hazardous products and road transport with regulations and basis in legislation and technical criteria is one of the main activities that allow the movement of these materials. This work has the purpose of evaluating the points most susceptible to accidents with environmental and social risks, involving the transportation of chemical and hazardous products by highway BR 393, named Rodovia Lúcio Meira. The section studied corresponded to Km 234 (Municipal limit of the city of Volta Redonda and the city of Barra do Piraí) to Km 282 (municipal boundary of the city of Barra do Piraí and the city of Vassouras). The aim was to evaluate the points most susceptible to accidents with environmental risks, as well as the identification, classification and emergency actions of the transported cargoes. Therefore, it can prepare measures for a preventative and integrated emergency plan among the mentioned Municipalities, avoiding environmental impacts from accidents and corrective actions if they happen.

Keywords: Road transport; Dangerous goods;: P2R2.
\end{abstract}

\section{Introdução}

Os acidentes ambientais são caracterizados como eventos não planejados e indesejados que podem causar direta ou indiretamente danos ao meio ambiente e à saúde da população (ABNT NBR ISO GUIA 73:2009). Atualmente, as organizações e a própria sociedade têmse deparado com a crescente necessidade de demonstrar seus compromissos com as questões ambientais e com o desenvolvimento econômico de uma sociedade, conduzindo o crescimento da produção industrial de produtos químicos e perigosos.

O transporte rodoviário com regulamentações, base e critérios técnicos na legislação brasileira é uma das principais atividades que possibilitam as movimentações desses materiais. É uma operação que apresenta uma série de riscos, uma vez que, nessas atividades, seja ela de carregamento, transporte, transbordo e acondicionamento, estes produtos estão sujeitos a uma série de situações adversas.

Os históricos de acidentes ambientais de grandes proporções, magnitude e consequências, desde a década de 60, ainda vem ocorrendo no Brasil e no mundo,

Afiliação dos autores: Universidade de Vassouras, USS, Vassouras-RJ, Brasil

* Email para correspondencia: crispereirauss@gmail.com 
onde se justifica a atenção ao tema (IBAMA, 2015). Em março de 2003, ocorreu um acidente ambiental no município de Cataguazes, Minas Gerais, ocasionado pelo rompimento de uma barragem contendo resíduos de substâncias químicas tóxicas perigosas, que atingiram os rios Pomba e Paraíba do Sul, acarretando grandes impactos na qualidade da água potável das cidades ribeirinhas e um desastre ecológico em termos de flora e fauna aquáticas.

Após esse acidente, tornou-se evidente a falta de um mecanismo de atendimento a emergências que se mostrasse eficaz em todo o território nacional, integrado aos sistemas estaduais. A existência de um mecanismo de atendimento a emergências eficaz poderia ter garantido um atendimento à disponibilização dos recursos materiais e humanos necessários em prazo adequado.

Naquela ocasião, em face do ocorrido, o Ministério do Meio Ambiente formou quatro grupos de trabalho direcionados para mapeamento de áreas de risco, construção de banco de dados, desenvolvimento estratégico e recursos financeiros. Como consequência do trabalho desses grupos, elaborou-se a proposta do Plano Nacional de Prevenção, Preparação e Resposta Rápida a Emergências Ambientais com Produtos Químicos Perigosos - P2R2. Em junho de 2004, durante a Semana do Meio Ambiente, assinou-se o Decreto Federal $\mathrm{n}^{\circ}$ 5.098, que criou definitivamente o P2R2, instituindo sua Comissão Nacional, definindo suas competências e incentivando a criação e a respectiva colaboração com as comissões estaduais e a distrital. Esse plano é, orientado pelos princípios gerais do direito ambiental brasileiro, tais como: da informação, da participação, prevenção, da precaução, da reparação e do poluidor pagador. Com isso, instituindo algumas diretrizes estratégicas:

a. O estimulo à adoção de soluções inovadoras que assegurem a plena integração de esforços entre o poder público e a sociedade civil, especialmente no âmbito dos Estados e Municípios;

b. Definição das responsabilidades respectivas do poder público e dos setores privados em casos de acidentes com produtos perigosos, e dos compromissos a serem assumidos pelas partes de proteger o meio ambiente e a saúde da população;

c. Assegurar ao cidadão à informação sobre os riscos de acidentes com produtos perigosos;

Mobilização de recursos humanos e financeiros apropriados e suficientes para assegurar os níveis de desempenho do plano e; d. Fortalecimento da capacidade de gestão ambiental integrada dos órgãos e instituições no âmbito federal, distrital, estadual e municipal, para o desenvolvimento de planos de ações conjuntas, no atendimento a situações de emergências envolvendo produtos perigosos, no sentido de ampliar a capacidade de resposta.

Entretanto, para o desenvolvimento do plano na tipologia Rodoviária são necessários instrumentos formais que visem à sua consolidação, como o Sistema de Informações de dados, o Mapeamento das Áreas de Risco, a elaboração e permanente revisão dos Planos de Ação de Emergência e a viabilização dos Mecanismos Financeiros de Apoio.

\section{Estudo de caso}

\section{Mapeamento das áreas de risco}

Foram caracterizados $10(\mathrm{dez})$ pontos susceptíveis a acidentes rodoviários com possibilidades de impactos ambientais em especial aos recursos hídricos, sendo 8 (oito) deles próximos ao Rio Paraíba do Sul. Essas áreas são da maioria das vezes retas que contribuem significativamente para os excessos de velocidade e ultrapassagens, ou seja, por longas jornadas de trabalho acontecem às falhas humanas, somadas ao mau acondicionamento da carga, proporcionando assim eventos indesejáveis com consequentes danos ao meio ambiente e a saúde pública.

As Figuras de 1 a 10 caracterizam trechos susceptíveis a acidentes, podendo causar danos ambientais e sociais.

Figura 1. Ponte sobre o Ribeirão do Inferno, Limite Municipal das Cidades de Barra do Piraí e Volta Redonda.

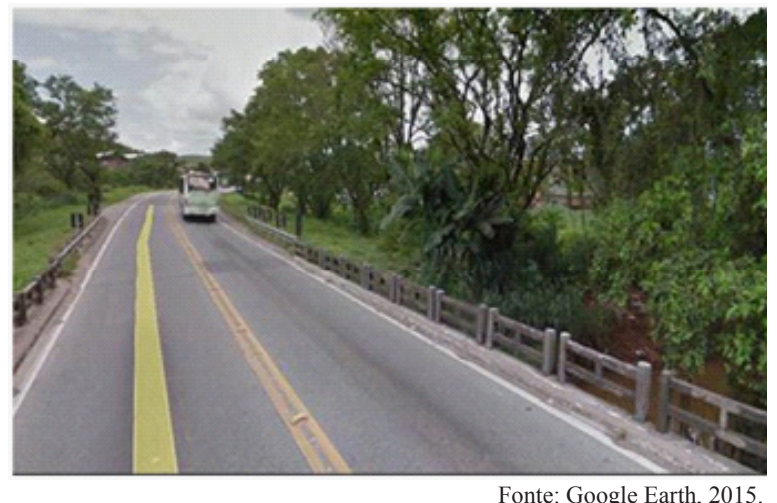


Figura 2. Ponte sobre o Ribeirão das Flores, Distrito da Califórnia.

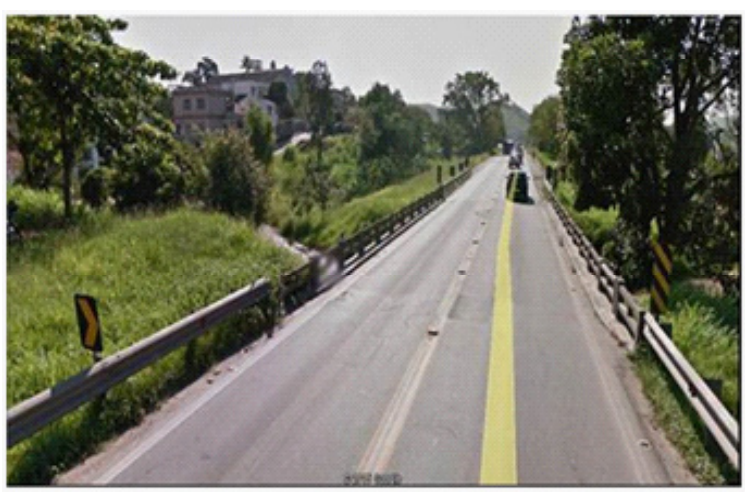

Fonte: Google Earth, 2015

Figura 3. Corpos Hídricos existentes na BR 393, Distrito da Califórnia.

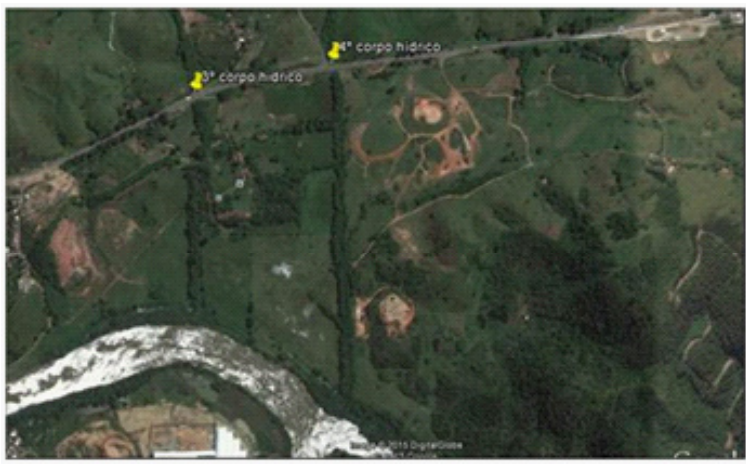

Fonte: Google Earth, 2015.

Figura 4. Ponte sobre o Ribeirão Boa Esperança, Distrito de Dorândia.

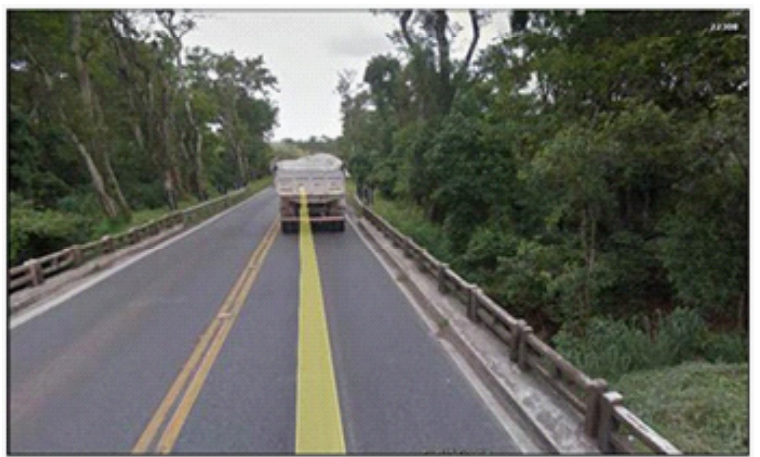

Fonte: Google Earth, 2015.

Figura 5. Ponte sobre o Ribeirão das Minhocas, Distrito de Dorândia.



Fonte: Google Earth, 2015
Figura 6. Ponte sobre o Ribeirão Ipiabas, Bairro Ponte Preta.

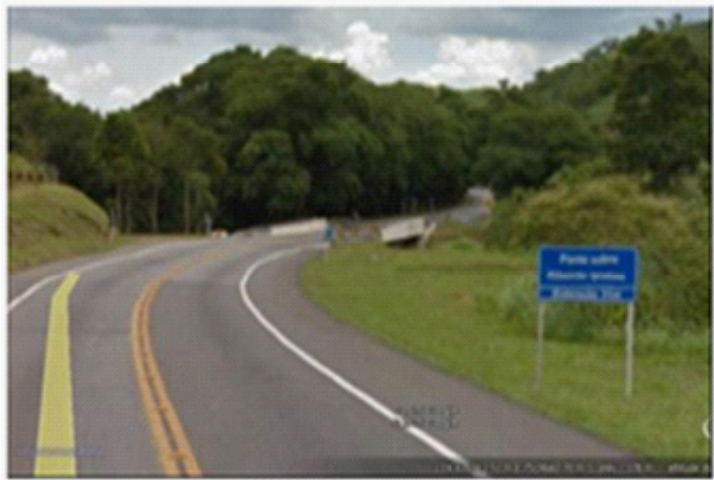

Fonte: Google Earth, 2015.

Figura 7. Ponte sobre o Ribeirão das Palmeiras, Bairro Coimbra

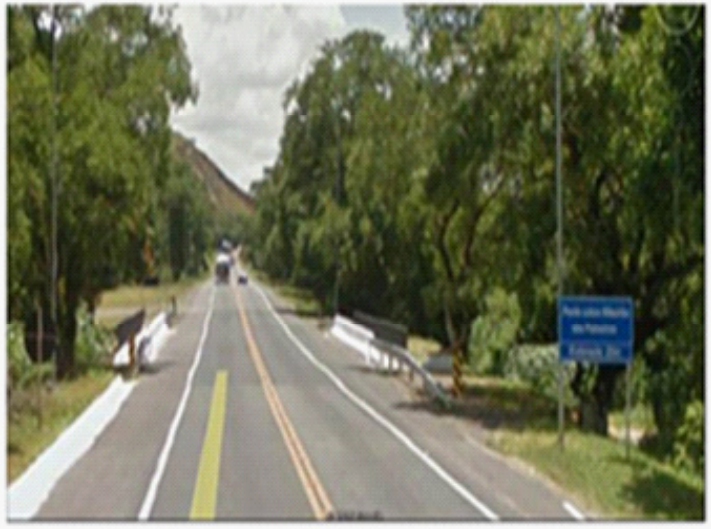

Fonte: Google Earth, 2015.

Figura 8. Curva do Aterrado, próximo ao posto da Polícia Rodoviária Federal.

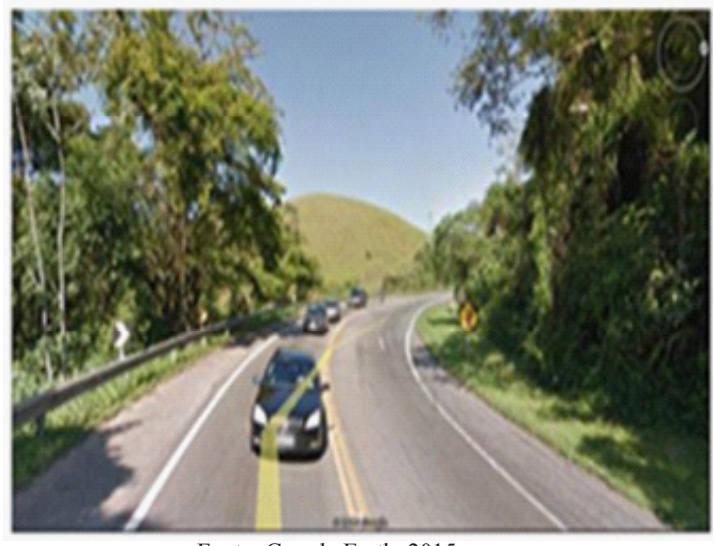

Fonte: Google Earth, 2015

Figura 9. Curva do Bairro Lago Azul.

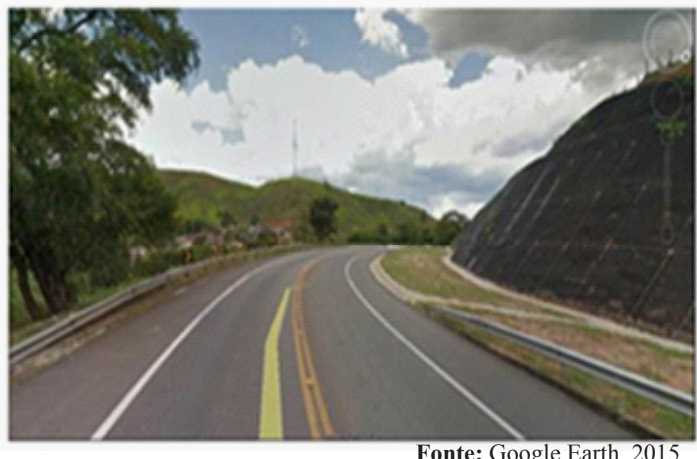


Figura 10. Ponte sobre o Ribeirão São Pedro, próximo ao limite Municipal de Barra do Piraí - Vassouras.

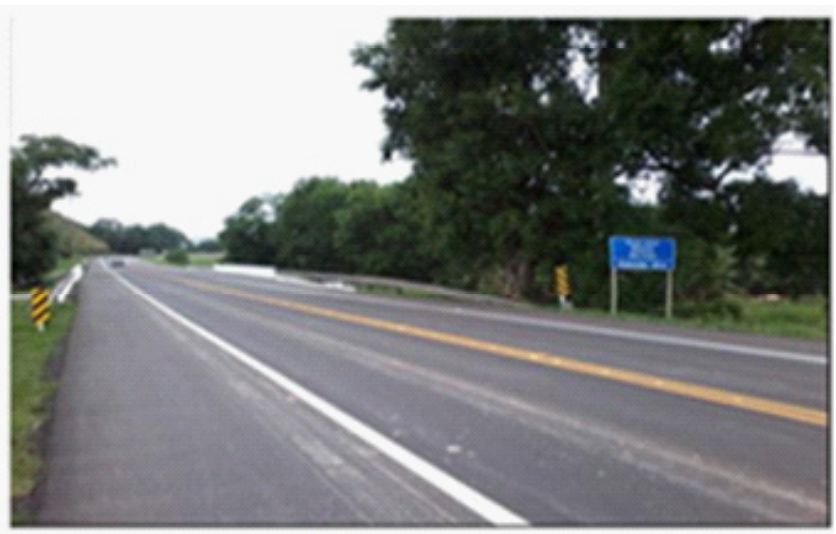

Fonte: Google Earth, 2015

\section{Sistema de informação (Banco de dados de Produtos Perigosos)}

O Estado do Rio de Janeiro, de acordo com dados fornecidos pelo Serviço de Operações em Emergências Ambientais - SOPEA apresenta também o índice de acidentes por tipologia envolvendo transporte de produtos perigosos. Este índice é apresentado na Figura 11.

Conforme a Figura 12 ilustrada abaixo, o Serviço de Operações em Emergências Ambientais - SOPOEA, em 2014 e 2015 apontaram nas Rodovias Federais BR116; BR-040; BR-393 e BR-101 e BR 493 os números de ocorrências ambientais.

$\mathrm{Na}$ tipologia Rodoviária, mesmo o transporte

Figura 11. Acidente no Estado do Rio de Janeiro por tipologia de transporte.

Indices de acidentes por Tipologia de Trânsportes

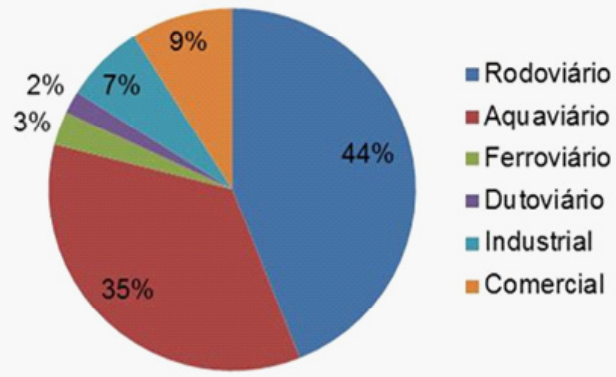

Fonte: adaptado de Serviço de Operações em Emergências Ambientais (SOPEA), 2015

Figura 12. Comparativo das Frequências de acidentes ocorridos em 2014 e 2015

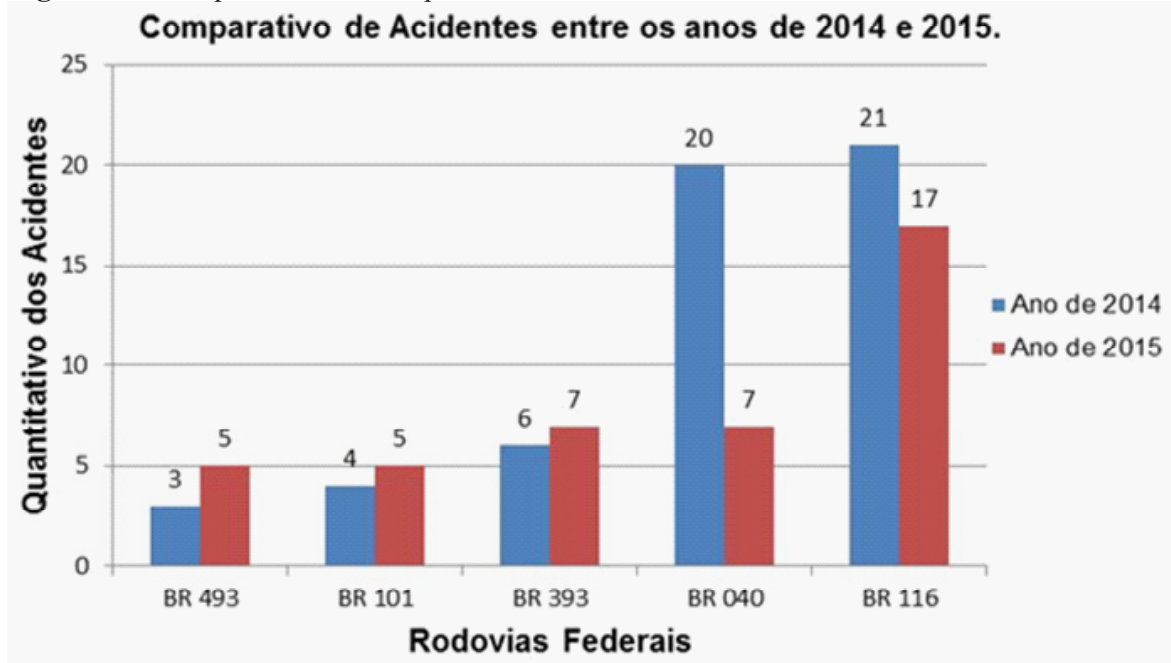

Fonte: adaptado de Serviço de Operações em Emergências Ambientais (SOPEA), 2015. 
de produtos químicos e perigosos tendo todas as suas Leis e Normas rigorosas para se evitar e minimizar os acidentes. No sistema de informações do Plano P2R2 é incluída também a relação de produtos perigosos que transitam na área de estudo, bem como, suas classificações de risco e numeração das Organizações das Nações Unidas (ONU). Observa-se na Tabela 1, a relação de alguns tipos de produtos que circulam com frequência no trecho em estudo da Rodovia BR 393, sendo esses dados coletados no posto de fiscalização da
Agencia Nacional de Transportes Terrestres ANTT no período de 14/02/2015 à 14/04/2015.

Após levantamento das informações (banco de dados) sobre os produtos perigosos que transitam pela BR 393, foram elaborados gráficos indicando as quantidades de caminhões, suas classes de risco e os produtos mais transportados. Estas informações são apresentadas nas Figuras 11e 12, tendo como referência o período de 14 de fevereiro de 2015 a 14 de Abril de 2015.

Tabela 1. Alguns produtos perigosos que são transportados na BR 393.

\begin{tabular}{lcc}
\hline Produto perigoso & N Da ONU $^{\circ}$ Classe de risco \\
\hline Soda Cáustica & 1821 & 8 (Subst. Corrosivas) \\
Oleo Diesel & 1202 & 3 (Liquidos) \\
Gasolina & 1203 & 3 (Liquidos) \\
Hipoclorito & 1791 & 8 (Subst. Corrosivas) \\
$\begin{array}{l}\text { Peróxido de Hidrogênio Solução aquosa } \\
\text { estabilizada }\end{array}$ & 2015 & 5.1 (Subst. Oxidantes) \\
Argônio Líquido & 1951 & 2.2 (Gases não inflamáveis não tóxicos) \\
Metilato de Sódio & 1431 & 4.2 (Sólidos Inflamáveis \\
Metanol & 1230 & Auto reagentes e explosivos sólidos insensibilizados) \\
Anidrido Acético & 1715 & 3 (Liquidos) \\
Acrilato de Butila & 2348 & 8 (Subst. Corrosivas) \\
\hline
\end{tabular}

Observa-se (Figura 13 e 14) que o fluxo de veículos transportando líquidos supera todas as outras classes de risco.

Observa-se ainda, na Figura 12, que o fluxo de veículos transportando óleo diesel e gasolina são os mais intensos que os demais, sendo um fator preocupante, pois eles são insolúveis em água e em caso de acidente poderia trazer grandes transtornos ao meio ambiente

Figura 13. Trânsito na BR 393 de caminhões e classe de risco dos produtos perigosos.

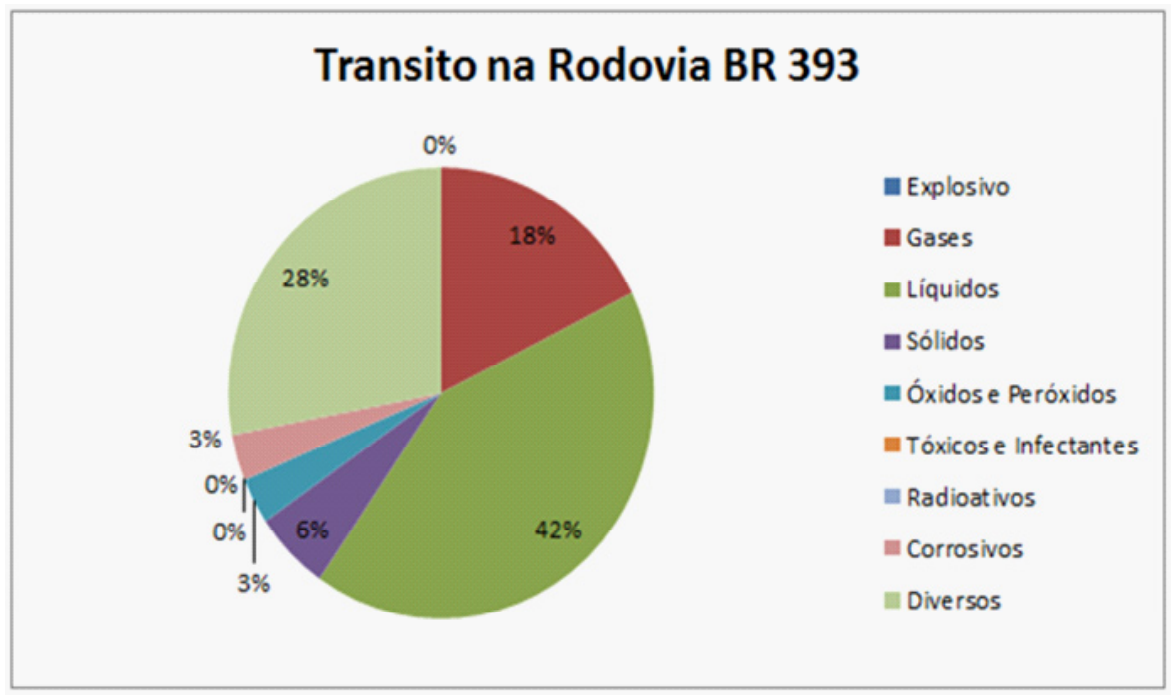

Fonte: Adaptado de ANTT, 2015. 
Figura 14. Frequência de trânsito de alguns produtos Perigosos na BR 393.



Fonte: Adaptado de ANTT, 2015.

\section{PAE (plano de ações a emergência)}

A intenção de um Plano de Ação de Emergência é fornecer um conjunto de diretrizes, dados e informações que propiciem as condições necessárias para a adoção de procedimentos lógicos, técnicos e administrativos, estruturados paraserem desencadeados rapidamente em situações de emergência, para a minimização de impactos à população e ao meio ambiente.

Outro aspecto a ser ressaltado diz respeito à implantação, manutenção e integração do plano com outros sistemas de resposta a emergências, sistemas estes, locais e regionais, além de um programa de treinamento, que contemple a realização de exercícios, teóricos e práticos, com vista a permanente atualização e periódica revisão do plano.

O sucesso de um atendimento a acidentes envolvendo otransporte rodoviário de produtos perigosos está diretamente relacionado ao tempo de resposta dos órgãos envolvidos, além da necessidade de informações precisas realizadas numa primeira avaliação.

\section{Mecanismos Financeiros de Apoio}

As principais atividades/processos envolvidos nesta etapa referem-se à estruturação das despesas operacionais, ou seja, equipamentos e treinamentos de pessoas, de custeio básico e estruturação das unidades organizacionais relacionado a logística, bem como, implementação dos instrumentos definidos para o plano, ou seja, o mapeamento de áreas de risco, a implementação de banco de dados e a estruturação dos planos de ação de emergência, se devendo buscar o desenvolvimento de mecanismos econômicos para a sustentabilidade financeira deste plano.

O setor público ambiental, poderá destinar parte das receitas obtidas com licenciamento e infrações ambientais para a implementação deste plano, favorecendo assim uma consolidação das leis ambientais e uma fiscalização mais eficiente e eficaz.

\section{Conclusão}

No presente estudo, avaliou-se a estrutura para uma resposta rápida ao atendimento às emergências ambientais no transporte de produtos químicos $\mathrm{e}$ perigosos, na tipologia rodoviária, nos limites municipais da cidade de Barra do Piraí, cidade na qual está localizada a transposição do Rio Paraíba do Sul para o Rio Guandu. O presente estudo não supre as necessidades no contexto de atendimentos a emergências ambientais, mas contribui para uma avaliação parcial da extensão da Rodovia (BR 393) possibilitando o desenvolvimento de novos estudos estendendo-se aos municípios vizinhos, para que seja construído um plano integrador de todos os municípios cortados pela Rodovia BR 393.

\section{Referências}

PLANO NACIONAL DE PREVENÇÃO, PREPARAÇ̃̃O E RESPOSTA 
RÁPIDA A EMERGÊNCIAS AMBIENTAIS (P2R2). Disponível em: <http: www.mma.gov.br>acesso em: 10 out. 2015;

AGENCIA NACIONAL DE TRANSPORTE TERRESTRE. Resolução $n^{\circ}$ 420, de 12 de fevereiro de 2004. Instruç̃es Complementares ao Regulamento do Transporte Terrestre de Produtos Perigosos. Disponível em $<\mathrm{http}: / / \mathrm{www}$. antt.gov.br/resoluções/00500/resolução420_2004.htm>. Acesso em: 10out. 2015

Manual para atendimento a Emergências com Produtos Perigosos, São Paulo: ABIQUIM, 2006.

INEA. Rio de Janeiro: Instituto Estadual do Ambiente. Disponível em: $<$ http:// www.inea.rj.gov.br/>. Acesso em: 15 out. 2015.

COSTA, M.A. Plano de Ação de Emergência Integrador:uma proposta com base no COMPERJ/CONLESTE. 2013. Tese (Doutorado) - Universidade Federal do Rio de Janeiro, 2013.

ACCIONA. Sobre a Rodovia do Aço. Disponível em: Http://www. rodoviadoaco.com.br. Acesso em 05 out. 2015.

DEPARTAMENTO NACIONAL DE INFRAESTRUTURA DE TRANSPORTE. DNIT. InfraestrutraRodoviária. Nomenclatura das Rodovias Federais. Disponível em:http://www.dnit.gov.br/. Acesso em 05 out.2015.

VIANA, V.J. Riscos ambientais associados ao transporte de produtos perigosos na área de influência da ETA Guandú - RJ, 2009. Dissertação (Mestrado) - Universidade do Estado do Rio de Janeiro, 2009. 